\title{
"Liberte-se dos rótulos": questões de gênero e sexualidade em práticas de letramento em comunidades ativistas do Facebook
}

"Free Yourselves from Label": Gender and Sexuality Issues in Literacy Practice in Activist Communities on Facebook

Fabiana Poças Biondo*

Universidade Federal de Mato Grosso do Sul

Campo Grande - Mato Grosso do Sul / Brasil

RESUMO: Este artigo analisa a construção de significados e a (des)construção de categorias identitárias de gênero e sexualidade em práticas de letramento, em comunidades do facebook. Oriento-me por pressupostos da teoria da performatividade dos gêneros e da teoria Queer, buscando discutir comentários de dois posts que abordam violências sofridas por seres humanos, encontrados em uma comunidade feminista e uma anti-homofóbica do facebook. Nesses comentários, é possível encontrar a convivência de significados mais ou menos tradicionais, subversivos e/ou transgressores sobre gênero e sexualidade, configurando um movimento multidirecional que, de certa forma, demarca a transgressão de valores acontecendo no espaço fronteiriço em que se apresenta nessas comunidades. A partir da hibridizaçâa e da mistura de categorias e vozes em processo, acredito ser possível (re)pensar as forças atuantes na configuração do sofrimento humano, especialmente no que diz respeito ao sofrimento relacionado a questóes de gênero e sexualidade, evidenciado neste texto.

PALAVRAS-CHAVE: Letramento Digital; Gênero; Sexualidade; Ativismo.

ABSTRACT: This article analyzes the construction of meanings and the (de) construction of identity categories of gender and sexuality in literacy practices in Facebook communities. This work is guided by the performative theory of gender and queer theory, and discusses commentaries of two posted messages dealing with violence against human beings in a feminist community and in an anti-homophobic community. In these comments, one can find an interaction

*fabibiondo@gmail.com 
of more or less traditional, subversive, and/or transgressive meanings on gender and sexuality, configuring a multi-directional movement that, to a certain extent, marks the transgression of values occurring in the border areas in which these communities lie. Through hybridization and the mixture of categories and voices in process within their activist spaces, it is worthwhile to (re)think the forces that act in the configuration of human suffering, especially as regards the suffering related to gender and sexuality issues analyzed in the text.

KEYWORDS: Digital Literacy; Gender; Sexuality; Activism.

\section{Introdução: O sofrimento humano como efeito e como uma causa $^{1}$}

\footnotetext{
"Eduarda ${ }^{2}$ nos deixou hoje porque quatro garotos acharam que estuprar uma garota de 15 anos não teria problema e distribuir uma foto que arruinou seu espírito e reputação seria divertido. (...) Essas são as pessoas que me tiraram minha linda garota."

(Postagem em comunidade do facebook, em abril de 2013)
}

"Apanhei do meu próprio pai quando assumi minha sexualidade aos 20 anos, fiquei hospitalizado em coma induzido por 3 dias, emagreci $10 \mathrm{~kg}$, e fiquei com muitas dores de cabeça! Apanhar foi o de menos, juro, pode parecer estranho, mas perto do que eu ouvi, foi o de menos."

(Postado em abril de 2013, em comunidade do facebook)

A escolha por iniciar este texto com os depoimentos acima representa uma opção deliberada por dar visibilidade ao que considero o principal ponto de entrelaçamento entre as questóes que pretendo problematizar aqui: o sofrimento humano. Materializado, inicialmente, no depoimento de uma mãe, cuja filha cometeu suicídio após ter sido vítima de estupro coletivo seguido de bullying (e no martírio da adolescente), bem como no desabafo de um jovem rapaz que sofreu agressões físicas e psicológicas do próprio pai em virtude de sua sexualidade - e nas possíveis angústias desse pai -, o sofrimento humano situa-se no entrecruzamento de práticas de participação em redes digitais de relacionamento e questôes de gênero e sexualidade aqui

\footnotetext{
${ }^{1}$ Agradeço ao Prof. Dr. Luiz Paulo da Moita Lopes pelas orientações que levaram à produção deste trabalho.

${ }^{2}$ Por motivos éticos, substituo por pseudônimos os nomes de todos os sujeitos envolvidos na pesquisa.
} 
destacadas. Diante dessas questôes, busco discutir como se dá a construção de significados sobre gênero e sexualidade, em interações realizadas em comunidades ativistas do facebook, mais especificamente em comentários de posts cujas temáticas evidenciam a violência e o sofrimento humano como constitutivos de formações culturais hegemônicas e binarizantes de gênero e de sexualidade.

Com esse propósito inicial, participei por cerca de seis meses como observadora em seis comunidades autocaracterizadas como feministas e anti-homofóbicas no facebook. Nesses espaços de afinidades, inicialmente chamou-me a atenção que, se por um lado eles potencializam o ativismo político, o questionamento de significados hegemônicos e, no limite, a transgressão de significados e identidades de gênero e de sexualidade, por outro lado, eles são reveladores da força cultural autoritária construída em torno do que se tem compreendido binária e essencialmente como ser homem/mulher, homossexual/heterossexual, bissexual, entre outras categorias tradicionalmente definidoras de identidades.

Essa mistura de vozes e verdades sobre identidades de gênero e sexualidade no mundo virtual reflete, em certa medida, a intensificação das transformaçôes sociais de nossos tempos, que têm se acelerado e tornado mais exacerbada a convivência de culturas e de estilos de vida. No caso das comunidades do facebook aqui focalizadas, vemo-nos diante de práticas socioculturais de letramento digital nas quais há infinita expansão de relações sociais, convidando-nos, como destaca Moita Lopes (2010, p.395), a "co-participar da vida de pessoas que não conhecemos, que desarticulam nossas concepçóes de mundo e ideologias, e que multiplicam os discursos a que temos acesso de forma ilimitada". Desse modo, "a tela do computador deixa de ser somente um local onde se busca informação e passa a ser principalmente um lugar de construção, de disputa, de contestação de significados" (MOITA LOPES, 2010, p.398).

Não obstante a potencialização dessas relações sociais no mundo digital, interessa-me compreender como se dá a construção de significados e a (des)construção de categorias identitárias de gênero e sexualidade nessas práticas de letramento digital específicas, à luz de teorias que procuram desestabilizar a naturalização de tais categorias, questionando suas próprias bases no interior das estruturas de poder que as constituem. Assim, orientome por princípios da teoria da performatividade dos gêneros (BUTLER, 2003, 2004; MOITA LOPES, 2007) e da teoria Queer (JAGOSE, 1996; 
NELSON, 2006; SALIH, 2012), seguindo uma visão de gênero e de sexualidade como não essenciais, não preexistentes à ação social e, logo, construídos performativamente no interior dessas açōes. É a partir dessa perspectiva que busco discutir a coexistência de significados tradicionais, subversivos e transgressores ${ }^{3}$ nessas comunidades, bem como problematizar as possíveis implicações políticas dessas açôes sociais na direção de seus objetivos ativistas.

Dessa forma, situo-me em um ambiente sócio-histórico que torna todas as afirmaçôes categóricas de identidade problemáticas e desestabilizadas, a fim de focalizar os temas e as hipóteses levantados especialmente a partir de comentários de dois posts encontrados em duas comunidades ativistas do facebook. Em comum, as duas postagens abordam violências sofridas por seres humanos, assim como as postagens da epígrafe. Esse movimento de análise se pretende em sintonia com questôes sobre as quais mais me interessa chamar a atenção frente à enorme quantidade de assuntos e comentários disponibilizados em comunidades ativistas de gênero e sexualidade na Internet. O sofrimento humano, assim, é pano de fundo não apenas das "lutas" empreendidas nas comunidades nas quais participei como leitora, mas também do próprio percurso empreendido neste trabalho.

A seção a seguir procura circunscrever sócio-historicamente esse percurso.

\section{Mundo contemporâneo, letramento digital e ativismo político: identidades e "pós-identidades"}

Conforme atestam diversos estudiosos que se dedicam a compreender as variadas facetas da vida contemporânea, são bastante evidentes as mudanças de natureza social, política, cultural, econômica e tecnológica que vivenciamos na atualidade. No cerne dessas mudanças, destacam-se os grandes avanços tecnológicos que testemunhamos nas mais diversas áreas da vida social, que promovem, entre outras coisas, uma integração global da informação e das relações, uma vez que assistimos, como atesta Castells (1999, p.40), a um crescimento exponencial das redes interativas de computadores, "criando novas formas e canais de comunicação, moldando a vida e, ao mesmo tempo, sendo moldadas por ela".

\footnotetext{
${ }^{3}$ Entendo esses três conceitos em um contínuo, no qual "transgredir" ("ir além”; "atravessar") ocuparia uma posição mais favorável em direção à cidadania.
} 
A despeito das vantagens que o desenvolvimento tecnológico proporciona à vida social, no interior do imenso campo de possibilidades por ele aberto emergem, a cada dia mais, as consequências coercivas de um mundo governado pelo mercado consumidor, colonizado pelo capital e enormemente caracterizado pela exclusão daqueles que não têm acesso aos seus benefícios. Em contrapartida, aqueles que ocupam lugares no topo do poder econômico manifestado nesse sistema podem se beneficiar do fato de o poder ter se tornado "extraterritorial", como sugere Bauman (2001), uma vez que não mais se limita nem se desacelera em função das antigas fronteiras espaço-temporais, atualmente transgredidas ao simples toque de um telefone celular.

Se, por um lado, a possibilidade de o poder se mover extraterritorialmente configura um processo de exclusão daqueles que a ele não têm acesso, por outro lado, essa mesma derrocada dos limites espaciais e temporais pode favorecer, em certa medida, a democracia e a cidadania. Assim, pondera Moita Lopes (2006, p.92), talvez a maior contribuição de nossos tempos seja a possibilidade de ensaiar a vida de outras pessoas para além das restrições locais, nos tirando "de nosso mundo e de nossas certezas que apagam quem é diferente de nós e não nos possibilitam viver outras formas de sociabilidades".

De modo semelhante, Beck et al (1997) sugerem que os tempos atuais favorecem um projeto de ação reflexiva por parte dos indivíduos que, ao se confrontarem com suas subjetividades e com as alteridades em um mundo globalizado, podem se tornar mais capazes de questionar constantemente as estruturas sociais e de abrir espaço ao "outro", superando as relaçôes locais e estimulando, em muitos casos, uma postura crítica ativa. Dessa forma, os autores acreditam que o mundo contemporâneo, mundo da "modernização reflexiva", é caracterizado pela possibilidade de se criar uma sociedade melhor, por meio de uma reflexividade altamente desenvolvida, que impele à consciência universal e favorece o ativismo. Eles se opõem, assim, a visões bem menos positivas desenvolvidas por autores que consideram que a fragmentação cultural e identitária, constitutiva do mundo atual, "paralisa" a atuação política, imobilizando açôes em direção à democracia e à cidadania.

A partir da sugestão de Fridman (2000, p.75) para que "não se duvide da colonização do inconsciente no capitalismo tardio, mas que também não se minimizem o campo de iniciativas e as possibilidades de ação de homens e mulheres contemporâneos na politização do cotidiano", compartilho da crença na possibilidade de intensificação dos movimentos políticos no mundo 
atual, aliada à ideia de Bauman (2001) de que, diante do intercruzamento dos múltiplos estilos de vida de grupos e culturas no mundo atual, a comunicação entre esses grupos pode assegurar a pluralidade em detrimento da limitação de significados. Advogo, assim, a favor da "pluriversalidade" (MOITA LOPES, 2006, p.89) da compreensão e do conhecimento na construção da cidadania, compreendendo as comunidades ativistas do facebook aqui investigadas como autênticas iniciativas nesse sentido.

Compreendo essas comunidades, ainda, como práticas sociais situadas por meio das quais os sujeitos constroem significados sobre o mundo social em espaços da Internet. Dessa forma, considero-as como práticas de letramento específicas da web 2.0, ou seja, como "novos letramentos" digitais, conforme Moita Lopes (2010). De acordo com o autor, esses letramentos podem ser considerados práticas sociais situadas pelo fato de envolverem atores sóciohistoricamente localizados e participando colaborativamente na coconstrução de significados no mundo digital, por meio de elementos multissemióticos (textos, imagens, vídeos, sons etc.). No caso das comunidades aqui em foco, especialmente significados sobre gênero e sexualidade.

Ao atuar colaborativamente na construção de significados na Internet, sujeitos socialmente situados entram em contato com discursos desestabilizadores da vida social e agem, nesses espaços dos quais participam à medida que os constroem, por meio da negociação, do agenciamento, da contestação e, no limite, da transgressão de significados naturalizados e fixados pela tradição. Assim, o mundo contemporâneo e, mais especificamente, os letramentos digitais nos colocam diante da desestabilização, do hibridismo e, especialmente, "cara a cara" com a alteridade, trazendo inevitavelmente para o foco da atenção a "identidade" - "essa certeza de que pertencemos a um determinado grupo ou comunidade", que se afirma "no contato com aqueles em que percebemos a diferença, o outro" -, afinal, a "contrapartida da identidade é a alteridade" (CARVALHO, 2010, p.22).

Além da potencialização do contato com a alteridade, propiciado pelo desenvolvimento da tecnologia digital, é fato que a desestabilização das instituições e das "verdades" com as quais costumávamos conviver faz com que muitos se coloquem na empreitada de repensar as suas identidades, ou de "procurá-las" a todo custo, inclusive (talvez especialmente) na religião e nos discursos fundamentalistas. Desse modo, Fridman (2000, p.63) destaca que a pós-modernidade tornou muito difícil a tarefa da "autoconstituição", uma vez que "as instituiçôes vivem se desfazendo e sendo continuamente reprojetadas". 
Paradoxalmente a esse movimento de busca por respostas que satisfaçam nossos questionamentos sobre "quem somos", as identidades se mostram cada dia mais transitórias e incompletas, um verdadeiro "devir", muito mais do que um elemento estável e coerente; especialmente na Internet, onde vemos uma multiplicação ilimitada de discursos, que eleva infinitamente as relações sociais e integra a vida de pessoas desconhecidas com suas culturas e sociabilidades bastante diversificadas.

No caso do gênero e da sexualidade, a compreensão e a problematização do modo como a construção de significados em práticas específicas de letramentos digitais (des)estabilizam categorias de identidades, bem como as implicações políticas dessas ações em direção ao ativismo, balizam minha trajetória na tentativa de colocar em questão o próprio conceito de identidade. Nessa direção, Moita Lopes (2011) nos orienta a questionar a estabilidade dos gêneros e das sexualidades pelo viés da incerteza, do hibridismo, da instabilidade, de forma que pudéssemos falar, talvez, em "pós-identidades", ao invés de identidades, e, dessa forma, talvez a questão atualmente não seja mais "quem somos?", e sim "o que estamos nos tornando?", "o que podemos ser?"

Essas questôes ecoam nas teorias de gênero e sexualidade que norteiam este texto - a teoria da performatividade e a teoria queer - e são a elas que me dedico mais particularmente a seguir.

\section{Problematizando categorias de gênero e sexualidade: teoria da performatividade e teoria Queer}

Logo nas primeiras páginas de um de seus mais influentes estudos, Judith Butler lança a seguinte questão: "Qual a melhor maneira de problematizar as categorias de gênero que sustentam a hierarquia dos gêneros e a heterossexualidade compulsória?” (BUTLER, 2003, p.8). Embora a autora não ofereça nenhuma resposta imediata e muito menos definitiva para a questão - não o faz, aliás, em nenhuma das outras muitas perguntas que mantém estrategicamente abertas à reflexão e à problematização, conforme lembra Salih (2012) - o percurso por ela empreendido nas páginas seguintes parece ter essa indagação como um dos principais eixos a nortear a (des)construção de sentidos sobre gênero e sexualidade, que ela coloca em ação por meio de sua escrita.

No interior desse questionamento provocador, que possibilita muitas das reflexões a orientar o presente trabalho, emerge o que talvez possa ser considerado o principal empreendimento de Butler (2003, p.38): a 
problematização e desestabilização da noção culturalmente situada segundo a qual "o sexo, o gênero, a prática social e o desejo" estariam em uma suposta relação de "coerência e continuidade".

Segundo essa visão bastante difundida, explica Salih (2012, p.67), o sexo, o gênero e a sexualidade implicar-se-iam mutuamente e, sendo assim, exemplifica a autora, "se alguém é biologicamente fêmea, espera-se que exiba traços 'femininos' e (num mundo heteronormativo, isto é, num mundo no qual a heterossexualidade é considerada a norma) tenha desejo por homens". Essa seria, portanto, a "norma" a definir a inteligibilidade do gênero e, "do ponto de vista dessa cultura, certos tipos de 'identidade de gênero' parecem ser meras falhas do desenvolvimento ou impossibilidades lógicas, que não se conformam à matriz de inteligibilidade instituída" (BUTLER, 2003, p.39).

Advogando em favor da "subversão" e da "desordem" dessa matriz de inteligibilidade do gênero, Butler (2003) busca primeiramente desconstruir a conexão aparentemente "inevitável” entre sexo e gênero, ao declarar que

o gênero é "não natural"; assim, não há uma relação necessária entre o corpo de alguém e o seu gênero. (...) Em outras palavras, é possível ser uma fêmea "masculina" ou um macho "feminino". (...) "por definição, o sexo se revelará ter sido gênero o tempo todo" (BUTLER, 2003, p.8 in SALIH, 2012, p.67).

É a partir dessa visão desessencializada do gênero que se desenvolvem os movimentos discursivos de Judith Butler, no sentido de descrever e problematizar "os processos pelos quais nos tornamos sujeitos ao assumir as identidades sexuadas/'generificadas'/racializadas, que são construídas para nós (e, em certa medida, por nós) no interior das estruturas de poder existentes" (SALIH, 2012, p.11). Como sugere a expressão "assumir as identidades que são construídas para nós e por nós”, Butler (2003) assume uma visão de gênero que o compreende como construída performativamente no interior das ações sociais às quais, desse modo, não preexistem: “(...) não há identidade de gênero por trás das expressōes de gênero; essa identidade é performativamente constituída, pelas próprias 'expressões' tidas como seus resultados" (BUTLER, 2003, p.48).

Essa visão performativa do gênero implica, entre outros pontos, assumir uma genealogia crítica na investigação da constituição do sujeito, por meio da qual é possível descrever os processos pelos quais as identidades são 
construídas no interior da linguagem e do discurso. ${ }^{4} \mathrm{~A}$ investigação genealógica das identidades de gênero permitiria, conforme Butler (2003), a verificação de que as identidades não se conformam aos binarismos de gênero criados no interior da matriz heterossexual (macho/fêmea; homem/mulher; heterossexual/ homossexual), transcendendo-os e evidenciando as instabilidades das categorias binárias de gênero e sexualidade. Essas categorias precisam ser radicalmente repensadas e compreendidas como efeitos de uma formação específica de poder, a sustentar a hierarquia dos gêneros e a heterossexualidade compulsória.

Essa negação dos essencialismos do gênero empreendida por Butler (2003) tem como um de seus principais desdobramentos a crítica que a autora faz a políticas feministas que centram suas ações em um "sujeito mulher", fundamentando-se nessa "identidade comum" que, para a autora, "impede uma investigação radical sobre as construções e as normas políticas da própria identidade" (BUTLER, 2003, p.10). Conforme destaca Butler (2003), uma política feminista que insiste numa alegação universalista e numa unidade da categoria "mulheres" - como observado muitas vezes nos discursos feministas de 1960-1970, centrados na libertação da mulher (SALIH, 2012) - acaba por excluir a multiplicidade constitutiva das identidades (que se entrecruza com outras modalidades performativas, como etnia, raça, classe social, sexualidade, etc.), bem como ignora as intersecçôes "culturais, sociais e políticas em que é construído o espectro concreto das 'mulheres" (BUTLER, 2003, p.35).

A possibilidade de o termo "mulheres" não supor uma identidade comum seria, portanto, uma forma de libertar a política feminista das consequências coercivas dessa construção, que acaba por gerar muitas recusas à sua aceitação e não possibilita a verificação de que o poder atua no mesmo campo de forças que é encoberto pela afirmação fundamentalista do sujeito feminista, "já que predetermina e fixa o sujeito que almeja liberar" (PENNYCOOK, 2006, p.80). Para Butler (2003, p.23), a política feminista precisa "contestar as próprias reificações do gênero e da identidade", tomando "a construção variável da identidade como um pré-requisito metodológico e normativo, senão como um objetivo político":

\footnotetext{
${ }^{4}$ Butler utiliza o termo "discurso" a partir de Michel Foucault, que o considera como "'grandes grupos de enunciados' que governam o modo como falamos e percebemos um momento ou momentos históricos específicos. Foucault compreende os enunciados como eventos reiteráveis que estão ligados por seus contextos históricos" (SALIH, 2012, p.69).
} 
A crítica feminista tem de explorar as afirmações totalizantes da economia significante masculinista, mas também deve permanecer autocrítica em relação aos gestos totalizantes do feminismo. O esforço de identificar o inimigo como singular em sua forma é um discurso invertido que mimetiza acriticamente a estratégia do opressor, em vez de oferecer um conjunto diferente de termos. (BUTLER, 2003, p.34).

Identificamos, assim, a sugestão de um movimento para as políticas ativistas de gênero e sexualidade no sentido de deslocar a disputa pelo poder, ou mesmo pela "igualdade" entre "homens", "mulheres", "homossexuais", "heterossexuais", etc., para a problematização dessas construções identitárias reguladoras, por meio das quais o poder atuaria na contramão dos objetivos de tais políticas emancipatórias. É por esse motivo que os pensamentos de Butler têm sido vistos como indispensáveis ao feminismo pós-moderno, levando "a teoria feminista a um novo patamar" (SALIH, 2012, p.63), bem como tomados como extremamente influentes à teoria queer, fazendo com que Butler "seja vista por muitos como a teórica queer por excelência” (SALIH, 2012, p.18).

Em sintonia com essa ideia de desconstrução da aparente "normalidade", ou "essencialidade" do sujeito, do seu sexo, gênero ou desejo sexual, o termo "queer" - cuja tradução remete a "estranho", "anormal", "não natural" caracteriza-se como uma forma antiga e pejorativa de se referir a homens e a mulheres homoeróticos (por ofensa ou por insulto), da qual os teóricos queer teriam se apropriado exatamente por "sua resistência à definição - por assim dizer - fácil” (SALIH, 2012, p.19). Moita Lopes (2011) sugere que o termo queer teria sido adaptado, na criação dos construtos dessa teoria, para dar conta de questôes significativas, ou seja, para problematizar questóes relacionadas a "modos de viver", a "formas sociais sempre em construção", a um estado contínuo de "tornar-se". Desse modo, continua o autor, não é possível dizer que exista uma "essência" a determinar a posição queer, uma vez que essa posição se configura justamente por lógicas avessas à própria lógica, como as lógicas "da instabilidade", "da incerteza", "da hibridade".

É possível inferir, assim, que, se por um lado a teoria da performatividade dos gêneros de Butler (2003) tem implicações essenciais na desnaturalização das categorias de gênero que, para a autora, sustentam a hierarquia dos gêneros por meio de sua constituição binarizante (homem x mulher), por outro lado, essa teoria também produz impactos importantes para a problematização das categorias referentes à sexualidade que sustentam a heterossexualidade compulsória: 
a "unidade" do gênero é o efeito de uma prática reguladora que busca uniformizar a identidade do gênero por via da heterossexualidade compulsória. A força de sua prática é, mediante um aparelho de produção excludente, restringir os significados relativos de "heterossexualidade", "homossexualidade" e "bissexualidade", bem como os lugares subversivos de sua convergência e re-significação (BUTLER, 2003, p.57).

Essa visão da autora sobre o efeito regulador da criação de identidades fixas e unívocas de gênero e sexualidade ecoa no pensamento de Foucault (1981 apud JAGOSE, 1996), segundo o qual as identidades sexuais consideradas marginalizadas não podem ser vistas, simplesmente, como vítimas das operações de poder. Ao contrário, para o autor, essas identidades são produzidas por essas mesmas operações, uma vez que a subjetividade moderna só pode ser vista como um efeito das redes de poder. Em outras palavras, pode-se dizer que a identidade é construída pela própria ideologia, ao invés de por resistência a ela (JAGOSE, 1996). Nelson (2006, p.227) salienta que a teoria queer tem por principal característica desestabilizar a clareza ou unidade das identidades sexuais categorizadas, uma vez que essas identidades "podem excluir e incluir, limitar e libertar", já que "o propósito do binário heterossexual/gay não é meramente descrever identidades sexuais, mas regulá-las; em outras palavras, o binário não é neutro, mas normativo" (NELSON, 1999, p.376 in NELSON, 2006, p.227).

Segundo Moita Lopes (2007, p.83), Foucault mostrou que o binário normativo (heterossexual/gay) se firmou a partir do discurso sexológico da Biologia do final do século XIX, que teria criado o conceito "homossexual", definido quem se encaixa em cada um dos lados do binômio e produzido "o conceito de homossexual como 'espécie' desviante da norma, isto é, da heterossexualidade". Assim, a teoria da performatividade dos gêneros e seu desdobramento na teoria queer, pautadas na investigação genealógica de Foucault, têm permitido "desconstruir visões essencializadas e biologizantes da homossexualidade e da heterossexualidade" que proclamavam a primeira delas como "desvio da 'norma".

Não haveria, portanto, uma essência a respeito do que é "ser" homossexual, heterossexual, bissexual, transexual, etc., conforme Moita Lopes (2007, p.86), nem um destino sexual definitivo para ninguém, o que "propicia a redefinição do sentido de sexualidade em termos de fluidez, ambiguidade e provisoriedade". Por outro lado, as pessoas desempenham performances particulares de sexualidade, podendo fazer isso de forma dinâmica, por meio da construção de objetos de desejo diferentes em diferentes momentos de sua vida, ou em variadas práticas discursivas: 
"podemos nos posicionar de modos variados por meio de performances diversas de identidades sexuais, o que quer dizer também que as sexualidades estão continuamente sendo (re)feitas" (MOITA LOPES, 2007, p.86).

Como em um convite a esse fazer-se e refazer-se em termos de gêneros e sexualidades, Butler (2003) define sua visão das identidades de gênero e sexualidade em função de uma quebra total com a sua natureza essencializada e predefinida e, assim, suas teorias têm sido fundamentais para "um enquadramento da sexualidade que vai além da identificação lésbica e gay e, em vez disso, abraça a categoria mais ampla de queer" (JAGOSE, 1996; NELSON, 1999 in PENNYCOOK, 2006, p.80). Assim, a teoria queer se afasta de estudos lésbicos, gays e feministas que tomam a existência da categoria "sujeito" e que configuram suas açōes a partir desse sujeito, a saber: "a mulher"; "o gay", "a lésbica”.

$\mathrm{Na}$ direção dessa compreensão das identidades de gênero/sexualidade como não ajustáveis a rótulos, "etiquetas", definições, é que identifico as violências e os sofrimentos vividos por seres humanos, nas situações apresentadas na epígrafe deste trabalho, como efeitos da hierarquia dos gêneros e da heterossexualidade compulsória a se sustentarem por categorias definidoras de identidades culturalmente produzidas. É ainda nessa direção que busco mostrar as interações de outros dois posts de comunidades ativistas do facebook, a partir do instrumental analítico descrito na próxima seção.

\section{Instrumentos de análise: relacionando o verbal e o social}

Tomando a linguagem como mediadora por excelência das práticas sociais e como o que, de fato, as tecnologias digitais fazem circular (SANTAELLA, 2007) considero o diálogo escrito, nos posts das comunidades, como uma "ferramenta de mediação na construção social dos significados" (MOITA LOPES, 2010, p.402). Compreendida a conversa escrita dessa forma, a minha interpretação dos movimentos interacionais apresentados nas postagens busca ancoragem em estudos realizados a partir de tradiçôes e de conceitos da sociolinguística, da análise do discurso e da antropologia linguística, que buscam reconfigurar a noção de frame [enquadre] na análise de práticas interacionais face a face (GUMPERZ e GUMPERZ, 2011; PARK e TAKANASHI, 2011).

Adaptando esses estudos a práticas de escrita online, considero, a partir desses autores, a reconfiguração do conceito de frame, tradicional na sociolinguística interacional (GOFFMAN, 2002), para framing, de modo a atribuir mais destaque ao caráter situacional e interpretativo do conceito. Dessa forma, as perspectivas sociais que antes eram tidas como simples 
"molduras" de determinados discursos passam a ser vistas como parte constitutiva destes e, logo, identificáveis apenas em sua relação com a situação social. O framing passa, então, a compreender aspectos macro das interações, como a reprodução de ideologias, de relaçõos e de categorias sociais, no tratamento de micro práticas interacionais, moldando a constituição da cultura e da ordem social.

Dessa forma, conforme Gumperz e Gumperz (2011), os framings podem ser vistos como um locus para a reprodução dinâmica de pressupostos culturais e de organização social, e o gerenciamento desses framings tem a importante função de construir e/ou reproduzir estruturas e crenças sociais. $\mathrm{O}$ framing funciona, portanto, como um dispositivo de "filtragem", por meio do qual é possível transformar e reorientar princípios de conduta social em uma determinada situação em questão. Dessa forma, os autores destacam que há três ideias em particular que marcam a passagem para of framing, ideias intimamente relacionadas e advindas da sociolinguística e da antropologia linguística, que têm suas bases firmadas no conceito de framing ou são altamente relevantes para a sua existência: postura (stance ou stancetaking); estilo (style); e metalinguagem e ideologia de linguagem (metalinguistics and language ideology).

O conceito de postura, que interessa mais de perto às nossas análises, pode ser entendido como "atos dialógicos por meio dos quais os falantes se posicionam e se alinham em direção a uma entidade ou proposição, bem como em direção ao outro" (PARK e TAKAHASHI, 2011, p.186). Expandindo o footing de Goffman, estudos sobre a postura fornecem maior especificação das dimensões interpessoais e intersubjetivas de framings e de como os falantes se valem de recursos linguísticos neste processo, de modo a desempenharem e alternarem posicionamentos e papeis sociais, se posicionando e/ou se autodesignando como isso ou como aquilo.

Nas interações ocorridas nas postagens em evidência, busco compreender, à luz do instrumental analítico apresentado, o modo como os participantes negociam, com os demais, suas posturas no jogo da linguagem (co)construído, e o que isso tem a evidenciar em termos de (re)construção de significados sobre gênero e sexualidade, conforme análises a seguir.

\section{Construção de significados sobre gênero e sexualidades no facebook: tradição, subversão e transgressão}

As análises desta seção estão centradas em duas comunidades 
ativistas do facebook - uma anti-homofóbica e uma feminista ${ }^{5}$ - e, mais especificamente, em dois posts cujas temáticas giram em torno de violências contra seres humanos, que evidenciam efeitos de visões extremistas do gênero e da sexualidade. Os acontecimentos em destaque nesses posts foram noticiados em várias comunidades ativistas de gênero e sexualidade das quais participei como observadora, obtendo uma enorme quantidade de comentários em cada uma delas. A opção por discutir as interações estabelecidas nas duas comunidades focalizadas aqui representa uma tentativa de dar visibilidade a parte do que eu considero mais representativo do movimento de construção de significados empreendidos nessas comunidades e por mim identificado, durante os seis meses nos quais delas participei.

Sem pretensões generalizantes e por questão de espaço, apresento apenas trechos das interações estabelecidas por meio dos comentários em cada post. Os trechos omitidos estão marcados por [...] e referem-se a partes que considerei menos relevantes para demonstrar o movimento de construção de significados, mobilizado a partir de cada um dos posts de abertura. ${ }^{6}$

\section{Comunidade 1 - autodenominada "feminista" (mais de 70.000 seguidores} até abril de 2013)

Quando falamos em cultura do estupro, estamos falando da culpabilização da vítima. A mulher sempr
éculpada pela agressão que sofreu. Quantos relatos já ouvimos de garotas que foram abusadas por algum
parente durante a infäncia e levaram bronca da mãe ao invés de serem apoiadas?! É recorrente e muit
errado, é absurdo. A mulher é taxada pelo patriarcado como uma pessoa sexualizada, interesseira
provocativa (a Eva, da biblia, né?!), aquela que pede para ser estuprada.
Mãe bate na filha ao descobrir que ela era estuprada pelo pai
Na cidade de [...], em [...], uma mulher bateu na fillha de 12 anos ao descobrir que a
garota era estuprada pelo marido. Segundo ela (...)
498 pessoas curtiram - 76 comentários

${ }_{5}^{5}$ Julguei adequado não apresentar o nome das comunidades do facebook que fornecem os dados da pesquisa, pois isso permitiria a fácil identificação do perfil dos sujeitos participantes.

${ }^{6}$ Como critério para seleção dos comentários a serem apresentados, utilizei a exclusão de comentários de teor semelhante aos apresentados, bem como daqueles não exatamente direcionados à temática em evidência nos posts. 


\section{Comentários: ${ }^{7}$}

Bruna -4 de abril (8:25)

50\% da culpa do patriarcado é das mulheres.

Respostas:

$\underline{\text { Lucas }-4 \text { de abril (10:59) }}$

Mas dá uma esperança enorme por um mundo melhor ver a consciência de algumas mulheres como vc.

Juliana - 4 de abril (11:24)

$100 \%$ da culpa do patriarcado é de pessoas como Bruna.

Kátia - 4 de abril (11:28)

é muito fácil falar quando não foi você que sofreu esse tipo de violência.

Carla -4 de abril (11:46)

Eu acho que $80 \%$ da culpa do patriarcado é das mulheres, porque somos nós que educamos os nossos filhos.

\section{Helena - 4 de abril (15:05)}

Claro, os homens nunca têm culpa de nada. Parabéns pra vocês. Se são as mulheres que educam os filhos já estão errando aí pois não deveria ser assim.

Luana -4 de abril (16:16)

Que bosta!

\section{Daiane -5 de abril (11:15)}

O patriarcado é feito pelos homens e imposto por eles, as mulheres são as VITIMAS dessas imposiçôes, crescem e formam seus com conceitos com elas, mas como em todo caso de agressões continuas, as vitimas sempre viram os maiores agressores.

Bruna -5 de abril (11:28)

Obrigada Carla por ser alguém que pensa fora da prisão do politicamente correcto e da

${ }^{7}$ Os comentários foram transcritos de forma fiel, sem preocupação em adequar a sua linguagem à norma padrão escrita da língua portuguesa. 
perpetuação naturalizante do lugar da mulher enquanto vítima (que isto sim, também faz parte da receita patriarcal). E Helena os Homens têm tanta culpa quanto as mulheres, estão é menos interessados em resolver o problema. Daiane, posso garantir-lhe que o patriarcado imposto por homens não funcionaria tão bem se as mulheres não o legitimassem numa base diária, como é o caso triste desta notícia.

Kamila - 4 de abril (8:20)

Oi?! Desânimo desse mundo!

Queila - 4 de abril (9:00)

O fato de muitas mulheres aceitarem tudo, apenas para ter um homem ajuda (e muito) a manter uma sociedade machista. Já vi muita mulher, que prefere apanhar, traição, humilhação, exploração e blábláblá pq acha que mulher que se preze não fica sozinha. Não é o primeiro caso de estupro pelo pai ou padrasto e não vai ser o último... Muitas vezes a mãe põe a culpa nos filhos e ainda se sente traida pela vitima, o nome disso é ABSURDO!

Respostas:

Mariana - 4 de abril (11:28)

Ou se sente tão insegura consigo mesma que tem ciúme e até mesmo "disputa" o "macho" com a filha, como é mostrado no filme Preciosa.

Bruna -5 de abril (11:44)

A guerra dos sexos é algo realmente interessante. Talvez o mundo fosse menos mau se fosse menos heterossexual.

Bruna inicia os comentários no post 1 com uma afirmação que dá margem à criação de uma polêmica: " $50 \%$ da culpa do patriarcado é das mulheres", questionando o sistema do patriarcado. Inicialmente, Bruna parece pautada em um discurso por meio do qual se institui a estrutura binária homem/mulher, porém, questionando uma posição historicamente constituída em alguns discursos feministas, a de que os "homens" seriam os culpados pelo patriarcado, ao colocarem a "mulher" numa situação de vitimização, sempre culpada e, como no post de abertura, "taxada pelo patriarcado como uma pessoa sexualizada, interesseira e provocativa". Para Bruna, portanto, "ser mulher" é ter 50\% de culpa do patriarcalismo, dividindo os outros $50 \%$ de "culpa" com o outro lado do binário - os homens. 
Em resposta a seu comentário "provocativo", Lucas, Juliana e Kátia posicionam-se e alinham-se contrariamente a Bruna, disputando com ela significados de gênero ao se apoiarem justamente no discurso que Bruna parece pretender questionar e reafirmando significados culturalmente situados, segundo os quais o "sujeito mulher" seria a única vítima do sistema patriarcal. O discurso de Lucas, de Juliana e de Kátia reafirma a força do patriarcado na constituição das mazelas sociais. Assim, questionam a (falta de) consciência de Bruna, atribuindo a pessoas que pensam como ela 100\% da culpa do sistema patriarcal e buscando deslocá-la imaginariamente para a situação da vítima da violência a fim de questionar a posição por ela assumida.

Na sequência, Carla (re)produz um discurso bastante tradicional e rebatido por políticas feministas desde sempre, que atribui ao sujeito mulher determinados papéis sociais específicos, como o papel de educar os filhos, contrariando, assim, tanto os significados acionados no post de abertura quanto os significados construídos nos comentários que antecedem ao seu. Por outro lado, Carla contesta os significados construídos por Juliana, Lucas e Kátia e se alinha a Bruna coconstruindo com ela significados questionadores do lugar do homem como culpado pelo sistema patriarcal, que estaria na base da situação de violência vivida pela garota que era estuprada pelo pai e que teria apanhado da mãe por conta do estupro sofrido. Os significados mobilizados por Carla revelam, ainda, uma das expressões a definirem a identidade da mulher em uma construção tradicional e pautada, a meu ver, em uma visão essencialista do sexo e dos gêneros: a responsabilidade exclusiva do "sujeito mulher" pela criação dos filhos.

Em comum, todos os significados construídos até o momento se alinham à existência de categorias de gênero a definir as identidades de "homem" e de "mulher", categorias que Butler (2003) rejeita até mesmo em favor de objetivos ativistas, por entender que o gênero não pode ser prefixado à ação social, como uma essência estabilizada e apenas refletida na linguagem. Ao contrário, para Butler (2003, p.47), "o gênero é sempre um feito, ainda que não seja obra de um sujeito tido como preexistente à obra”. Sendo assim, conforme a autora, o gênero não pode denotar "um ser substantivo, mas um ponto relativo de convergência entre conjuntos específicos de relações, cultural e historicamente convergentes" (BUTLER, 2003, p.29).

Opondo-se diretamente à postura e aos significados mobilizados por Carla, Helena reproduz, de forma aparentemente irônica e deliberada, um discurso feminista fundamentado na desconstrução do sistema denominado 
patriarcal - "os homens nunca têm culpa de nada" - ao mesmo tempo em que seu discurso reforça a essência binarizante dos gêneros, ao colocar a oposição homem/mulher em foco. Em seguida, questiona, no interior da performance de mulher feminista que ensaia, a ideia cristalizada por discursos fundamentalistas de que a mulher seria o sujeito responsável pela criação dos filhos, afirmando o "erro" do sujeito mulher que se alinha com essa visão, que "distribui" determinados papéis sociais ao homem e à mulher. Luana, por sua vez, posiciona-se em tom de revolta, talvez em relação à notícia, talvez aos comentários dos demais participantes.

Daiane, na sequência, se alinha com Helena na criação de significados que instituem as mulheres como "vítimas" de uma sociedade essencialmente patriarcal, imposta e desenvolvida pelos homens, ecoando discursos culturalmente situados, que costumam construir a identidade "mulher" de forma essencialmente fragilizada e vitimada, reforçando, na contramão de seus objetivos, estruturas de poder às quais, parece, procura se opor. Daiane acaba por se posicionar envolta em uma cultura marcada pela estabilização de identidades de gênero, reforçando a criação do binário homem/mulher no interior dessa cultura.

Para Butler (2003), as identidades marginalizadas não podem ser tomadas apenas como vítimas das estruturas de poder, mas é preciso identificar como o poder atua na própria instituição dessas identidades. Assim, pondera a autora, embora a crítica feminista deva questionar estruturas totalizantes que geram hierarquia dos gêneros, ela também precisa estar atenta aos "gestos totalizantes" que pode criar. No caso do discurso construído por Daiane, a categoria "homem" é identificada de forma singular, com atributo de culpa pelo patriarcado. À identidade das "mulheres", ao contrário, é atribuída a característica de vítima, marcando um gesto colonizador que, ao mesmo tempo, define e aprisiona o sujeito "mulher" e o sujeito "homem" por meio de expressôes coercivas de identidade de gênero.

Encerrando esse turno de negociações e disputas de posições e significados sobre gênero e sexualidade, Bruna se posiciona discursivamente, questionando a expressão cultural do "politicamente correto", entendido, neste espaço-tempo, como o fato de a mulher ser tomada como vítima, e a própria noção ou "perpetuação naturalizante" do lugar da mulher enquanto vítima. Dessa forma, Bruna gerencia significados sobre gênero a partir de toda a interação estabelecida até o momento, questionando os significados mobilizados por Daiane, Kátia, Lucas e Juliana que, segundo se entrevê em 
sua fala, estariam "imersos" nessa estrutura de poder por meio da qual o patriarcado que questionam, simultaneamente, se fortalece. Bruna ainda se alinha a Carla, em certa medida, colaborando com ela na produção de um discurso que procura problematizar os lugares culturalmente "sacramentados" da mulher como vítima e do homem como culpado. Posteriormente, Bruna volta a tentar "equilibrar" a parcela de responsabilidade pelo chamado sistema do patriarcado entre os homens e as mulheres, afirmando que não apenas os primeiros seriam responsáveis, mas também as mulheres, que também o legitimam "em uma base diária".

Kamila inicia um novo turno de produção de significados ao expressar seu "desânimo desse mundo" e provocar novos comentários, como o de Queila e Mariana, que se alinham na direção de um discurso pautado na visão do sujeito "mulher" com determinados atributos, como: "aceita tudo pra não perder o seu homem", "prefere apanhar, ser traída, humilhada e explorada a ficar sozinha", "é insegura", "disputa o macho com outras mulheres" - nesse caso, com a própria filha. Assim, ao mesmo tempo em que procuram se opor a um sistema de poder que seria "responsável" por essa condição da mulher na sociedade, afirmando que as mulheres são as vítimas de uma estrutura que pode torná-las “imóveis” diante dessas situações de exploração, Queila e Mariana acabam por colaborar na produção desses discursos, que instituem a "mulher" a partir de atributos especificamente situados e como um sujeito passivo na sociedade, vitimada pelo "outro", o "homem". Mais uma vez, aqui, é possível observar a força atuante da produção de categorias de gênero, mesmo na produção de um movimento ativista, a estabilizar estruturas de poder que, de outro modo, poderia questionar conceitos totalizantes a respeito do que se institui como "homem", como "mulher", e como relação de poder entre um e outro em nossa sociedade.

Finalizando sua participação na discussão, Bruna parece "brincar" com o binário homem/mulher e a oposição/diferença que ele implica, afirmando que "a guerra dos sexos é realmente interessante", e que "talvez o mundo fosse menos mau se fosse menos heterossexual". Nesse momento da fala de Bruna, chamo a atenção para a forma como ela se posiciona e se alinha na direção de uma subpolítica por meio da construção de significados desestabilizadores dos essencialismos de sexo e gênero. Seu discurso, portanto, parece construir-se sustentado em uma visão do gênero e da sexualidade, que busca problematizar as categorias definidoras de gênero e sexualidade que sustentam a hierarquia dos gêneros e a heterossexualidade compulsória, no 
caminho das teorias pós-feministas e queer que embasam este texto. Para Butler, "rir de categorias sérias é indispensável para o feminismo" (BUTLER, 2003, p.8).

\section{Comunidade 2 - autocaracterizada por fazer ativismo contra a "homofobia" (mais de 40.000 seguidores até abril de 2013)}

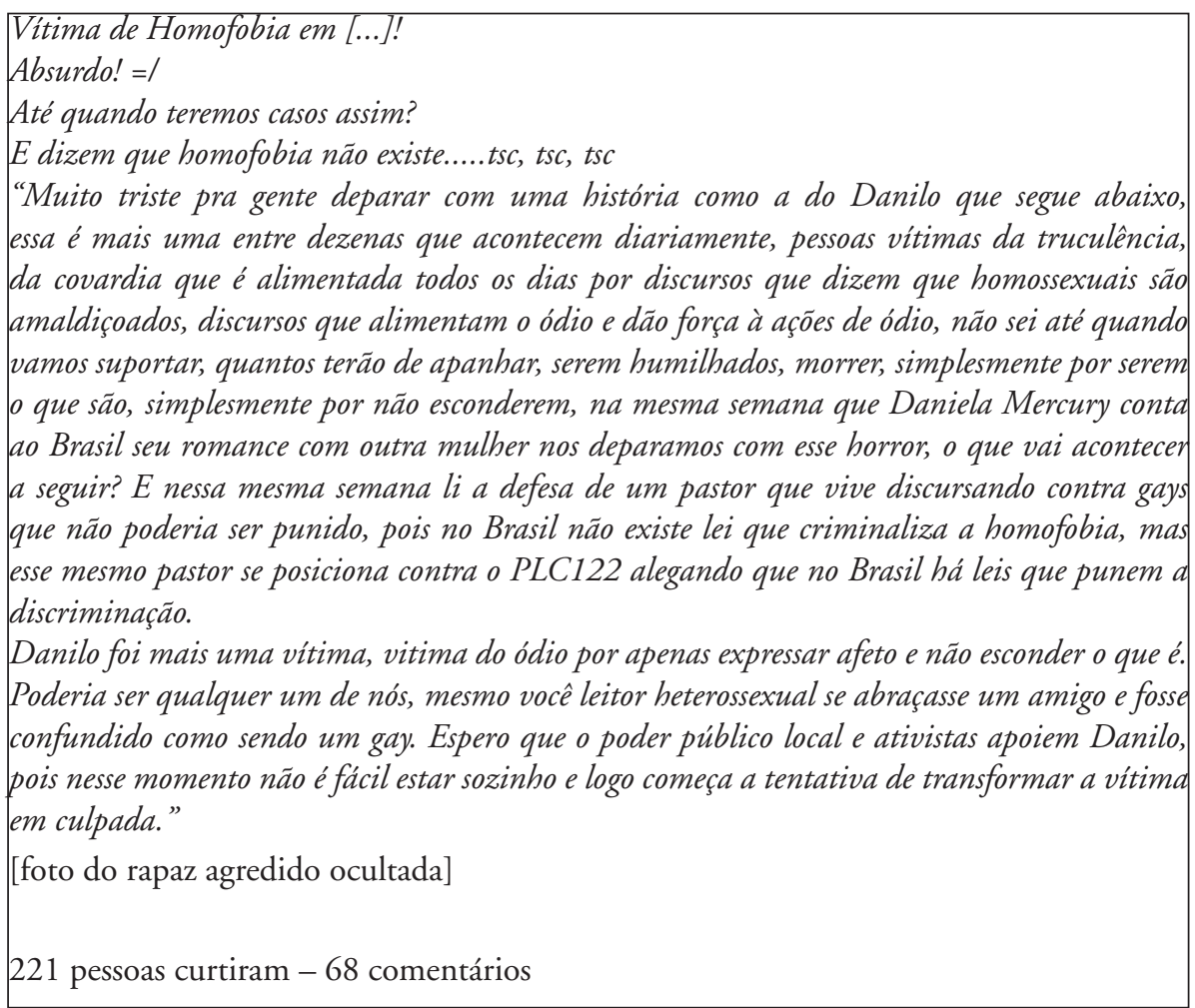

Comentários:

Manoela -8 de abril (11:00)

Ah claro.. Que ousadia do Gay querer ser alguém com direitos iguais na sociedade! Nossa, um absurdo mesmo o gay querer que a religiāo não se misture com o Estado. Agora aguenta o fato de querer viver como qualquer outro cidadão, né? Quem mandou sair do armário? Olha gente, pior que homofóbico ignorante, só gay homofóbico ignorante que abaixa a cabeça pros absurdos que acontecem.

Respostas: 
$\underline{\text { Cleuza }-8 \text { de abril (14:06) }}$

Concordo!

Ana Paula -8 de abril (14:59)

enquanto houver bandidos governando e inocentes sendo reprimidos por suas opçôes, teremos casos como este, infelizmente a humanidade tem condiçôes precárias de amor, infelizmente!

$\underline{\text { Larissa }-8 \text { de abril }(17: 14)}$

Enqto vcs perdem tempo crucificando o Feliciano, o PT e os demais membros da quadrilha estão roubando a gente, o nosso dinheiro! Enqto vcs pregam e EXIGEM (impóe a força a ditadura gay p/ a sociedade) os seus direitos/ igualdade (lembrando que a lei é igual p/ todos), os católicos e evangélicos irão pregar a fisolofia dogmática de suas religões e sempre terão idéias contrárias da comunidade GLSBT! Enqto vcs pregam o ódio e a "HUMANOFOBIA" em relação a etnia, religiāo e orientação sexual, ninguém vai entrar em acordo em teremos um mundo cada vez mais INTOLERANTE E IGNORANTE! ACORDA MEU POVO! VAMOS NOS UNIR CONTRA A CORRUPÇÃO NO BRASIL!

$\underline{\text { Larissa }-8 \text { de abril (17:03) }}$

Tanto homo como hétero, todos tem os mesmos direitos e deveres, então vamos respeitar as diferenças!

$\underline{\text { Ruan }-8 \text { de abril (18:51) }}$

Preguiça da geração do armário! (bocejando)

Manoela -8 de abril (19:04)

Parabéns por ser mais uma ovelhinha alienada que cai no conto do vigário dos pastores que usam a religiāo em interesse próprio. Quanto ao PT e "os demais membros da quadrilha", vc deveria pesquisar melhor e saber que mais de 50\% dos politicas da bancada evangélica responder por CRIMES. Pouquíssimos tem ficha limpa.

Então, não fale do que você realmente não sabe. Porque é vergonhosa o tamanho da sua ignorância.

[...] 8 comentários omitidos

Elisângela -10 de abril (20:05)

vc manoela deve ser uma mulher mau amada, nem homem deve querer te comer 
$\mathrm{O}$ post 2 abre as discussões a respeito do espancamento sofrido por um jovem rapaz em função de sua sexualidade "gay". O responsável pela postagem critica atitudes homofóbicas de pessoas que agem "covardemente"e com violência, em função de "discursos que dizem que homossexuais são amaldiçoados, discursos que alimentam o ódio e dão força a açôes de ódio". Assim, marca sua revolta contra esse tipo de violência e constrói significados sobre sexualidade, pautado em discurso que a determina como essência, ao afirmar a vitimização dos homossexuais por "serem o que são", por "não esconder o que é". Afirma ainda que a violência alimentada pelo ódio aos homossexuais pode acontecer com qualquer um, inclusive o "leitor heterossexual", desde que confundido como "sendo um gay".

Sua postura sustenta-se, assim, a partir de dois pilares apenas aparentemente opostos: o da construção de uma subpolítica a questionar e a combater a hegemonia de sexo e sexualidade; o do binário homossexual/heterossexual, ancorado em uma visão da sexualidade como essência. Informada especialmente pelo discurso sexológico da biologia do final do século XIX - conforme genealogia foucaultiana que situamos anteriormente -, essa concepção definiu o binário homo/hetero e cuidou de enquadrar os sujeitos em um e outro rótulo, definindo os homossexuais como desviantes da "norma".

Assim, embora o responsável pela postagem procure questionar essa norma, acaba por construir significados a partir dela, afinal, como nos lembra Louro (2008, p.22): "[a norma] está em toda parte. Expressa-se por meio de recomendaçóes repetidas e observadas cotidianamente, que servem de referência a todos. Daí por que a norma se faz penetrante, daí por que ela é capaz de se naturalizar". Ainda a esse respeito, Salih (2012, p.68-69) salienta que "a sexualidade culturalmente construída não pode ser deixada de lado, de modo que, para o sujeito, resta a questáo de como reconhecer e 'fazer' a construção na qual ele já se encontra".

Alinhando-se aos significados mobilizados na postagem de abertura, Manoela constrói significados sobre a sexualidade assumindo deliberada e ironicamemente a posição de sujeito contrário aos direitos igualitários dos gays, e valendo-se de discursos típicos desse lugar social de onde ela simula falar, como, por exemplo, "quem mandou sair do armário?", "um absurdo mesmo o gay querer que a religião não se misture com o Estado" a fim de criticar atitudes de violência como a noticiada na postagem. A exemplo do que ocorre no post, porém, Manoela reafirma o binário gay/não gay, enquadrando o primeiro em termos de identidade a despeito de todos os atravessamentos identitários que o constituem. 
De certo modo, marcar identidades parece bastante "natural" para que os sujeitos possam se definir de modo a fazer sentido no mundo social, especialmente no espaço-tempo ativista sob análise que, parece-me, "exige" que se assuma um projeto identitário. No entanto, não parece adequado ignorar que a marcação dessas identidades pode funcionar paradoxalmente aos objetivos emancipatórios de grupos ativistas, afinal, "ao classificar os sujeitos, toda sociedade estabelece divisões e atribui rótulos que pretendem fixar as identidades. Ela define, separa e, de formas sutis ou violentas, também distingue e discrimina" (LOURO, 2000, p.12).

Cleuza, na sequência, alinha-se a Manoela, afirmando concordar com suas proposições e Ana Paula, por sua vez, reforça significados sobre a posição de repressão dos "inocentes" que são reprimidos por "suas opçōes". Acrescenta, ainda, à discussão, um discurso segundo o qual os "bandidos" que estão no governo estão em relação de oposição com esses inocentes e reprimidos, demonstrando sua insatisfação para com esse quadro que, para ela, mostra que "a humanidade tem condições precárias de amor". Ana Paula coconstrói, assim, com o responsável pelo post, com Manoela e com Cleuza, significados sobre a sexualidade que demarcam as diferenças (que procuram combater) entre os homossexuais e os heterossexuais, a definir a fragilidade e vitimização dos primeiros em relação ao favorecimento social dos segundos, bem como associando o poder (aqui representado pela ocupação de lugar no governo) a sentimentos humanitários e religiosos.

Larissa alinha-se contrariamente aos comentários anteriores, assumindo uma posição religiosa bastante evidenciada em seu discurso e posicionando-se contrariamente ao que denomina de uma "ditadura gay" "imposta" para a sociedade por pessoas como Manoela, Ana Paula, o responsável pelo post e Cleuza ("vcs pregam", "vcs perdem tempo"). Além disso, Larissa tenta deslocar os significados relacionados à sexualidade para criar significados sobre o governo, em defesa do deputado/pastor bastante criticado por uma parcela da sociedade, em geral, nos últimos tempos, por sua postura considerada preconceituosa frente à presidência da Comissão dos Direitos Humanos; bem como a partir de um discurso de crítica partidária aos "membros da quadrilha" que, segundo ela, estariam discutindo e pregando a tal "ditadura gay" que ela nomeia.

$\mathrm{Na}$ sequência, Larissa disputa significados sobre a sexualidade com seu próprio discurso anterior, ao afirmar que "Tanto homo como hétero, todos tem os mesmos direitos e deveres" e conclamando um respeito "às 
diferenças". Nesse momento, Larissa coconstrói com os participantes anteriores significados sobre a sexualidade a partir do binário homo/ hetero. Esses significados, empreendidos coletivamente por sujeitos que, aparentemente, têm visões tão contraditórias, a meu ver acabam por reforçar as diferenças em sentido contrário aos objetivos ativistas da comunidade. A esse respeito, Louro (2008, p.22) destaca que "a diferença é produzida através de processos discursivos e culturais. A diferença é ensinada".

Como se pode observar a partir dessas postagens, coexistem, no interior do discurso de um mesmo participante da interação, assim como na troca discursiva estabelecida entre os participantes, significados mais ou menos transgressores de sexualidade nesse espaço-tempo de contestação de significados, informados pela naturalização da diferença (e de suas violentas consequências) observada nos comentários dos posts. O poder instituído na afirmação negativa das diferenças e firmemente questionado nessas comunidades, portanto, acaba por se materializar mesmo nesses questionamentos, marcando a (re)produção de significados bastante diversos sobre a sexualidade.

$\mathrm{Na}$ continuidade, Ruan ensaia uma performance identitária de gay e ironiza o que ele chama de "geração do armário", (re)produzindo um discurso tipicamente reconhecido como do lugar a partir do qual ele se posiciona, como gay, que tem "preguiça”" da geração que não "sai do armário". Dessa forma, Ruan alinha-se frente à construção de uma identidade bem delimitada para si, de modo a questionar os significados mobilizados por Larissa mesmo sem rebatê-los diretamente, apenas por meio da ironia com que demonstra sua posição e sua "preguiça" diante das coisas que ela diz.

Manoela, no entanto, questiona de forma bem diretiva os significados construídos por Larissa, dando-lhe ironicamente os "parabéns" e chamando-a de "ovelhinha alienada" que cai "no conto do vigário dos pastores que usam a religião em interesse próprio". Assumindo propositalmente os termos específicos do campo instituído como da religião, Manoela contraria a visão de Larissa sobre os pastores e o governo ao mobilizar dados estatísticos para afirmar que " $50 \%$ dos políticos da bancada evangélica respondem por CRIMES”. Assim, Manoela se alinha contrariamente à posição política e religiosa de Larissa, considerando "vergonhosa o tamanho da sua [da Larissa] ignorância”.

A interação continua nesse tom de disputas de significados sobre sexualidade, religião e política nos oito comentários aqui omitidos até que 
Elisângela "entra em cena", com um discurso que remete à proximidade da hierarquia dos gêneros com a questão da sexualidade compulsória. Nesse caminho, Elisângela constrói significados sobre gênero bastante imbuída no posicionamento do sujeito mulher, a partir de determinados papéis e estereótipos sociais, ao afirmar que Manoela "deve ser uma mulher mau amada, nem homem deve querer te [a] comer". Nesse momento, Elisângela aciona significados sobre "ser mulher" e sobre "ser homossexual" que estão em relação de determinação um para o outro, uma vez que remete ao discurso culturalmente situado segundo o qual as mulheres denominadas "gays" o são por serem "mal amadas" e/ou "mal 'comidas". A esse respeito, Butler (2003, p.57) destaca a relação íntima que se estabelece entre a hierarquia dos gêneros e a heterossexualidade compulsória ao afirmar que
a "unidade" do gênero é o efeito de uma prática reguladora que busca uniformizar a identidade do gênero por via da heterossexualidade compulsória. A força de sua prática é, mediante um aparelho de produção excludente, restringir os significados relativos de "heterossexualidade", "homossexualidade" e "bissexualidade", bem como os lugares subversivos de sua convergência e re-significação.

A análise dessas postagens sacramenta, assim, a relação de interdependência entre a hierarquia de gênero e a heterossexualidade compulsória, a definir posiçôes superiores e inferiores em nossa sociedade e a produzir e sustentar o sofrimento humano.

\section{Tradição, subversão, transgressão e sofrimento humano: considerações finais}

Neste trabalho, busquei discutir a construção de significados sobre gênero e sexualidade em interações estabelecidas, especialmente, a partir de dois posts selecionados de duas comunidades ativistas - uma feminista e outra anti-homofóbica. Nesse caminho, construo uma performance interpretativa, baseada em teorias da performatividade do gênero e teoria queer, analisando as relações entre a construção desses significados e os propósitos ativistas dessas comunidades.

No interior dos espaços-tempos criados a partir de objetivos ativistas aqui analisados, pude identificar significados sobre gênero e sexualidade ainda bastante pautados na essência do ser homem e ser mulher, bem como de ser homossexual, heterossexual, bissexual ou qualquer outro rótulo, a 
definir e restringir sexualidades instáveis e bastante mais complexas que esses rótulos são capazes de fazer supor. Embora a marcação de identidades fosse esperada em grupos ativistas, dada a importância de sua identificação enquanto grupo militante, esses significados, (co)construídos e (re) construídos de formas bastante diferentes pelos mais variados comentários encontrados nas comunidades, parecem operar na contramão de teorizaçóes queer e dos propósitos transgressores dessas comunidades.

Por outro lado, a convivência de significados mais ou menos tradicionais, subversivos e/ou transgressores no interior de tais comunidades é o que me pareceu mais evidente e significativo nesses meses em que delas participei como observadora e em que, com elas, busquei interpretar e construir significados sobre gênero e sexualidade, o que de fato é referendado na análise realizada. Essa convivência, parece-me, acaba por configurar um movimento mais multidirecional que contínuo entre esses significados, o que, de certa forma, demarca a transgressão de valores acontecendo e em movimento no espaço fronteiriço em que se apresenta nessas comunidades.

É a partir da hibridização e mistura de categorias típicas da transgressão que penso ser possível (re)pensar as forças atuantes na configuração do sofrimento humano. Especialmente no que diz respeito ao sofrimento relacionado a questôes de gênero e sexualidade e evidenciados nas comunidades do facebook, bem como na epígrafe e postagens deste texto.

\section{REFERÊNCIAS}

BAUMAN, Z. Modernidade líquida. Rio de Janeiro: Jorge Zahar, 2001. 255 p.

BECK, U. et al. Modernização reflexiva: política, tradição e estética na ordem social moderna. São Paulo: Editora da Universidade Estadual Paulista, 1997. 257 p.

BUTLER, J. Problemas de gênero. Feminismo e subversão da identidade. Trad.: Renato Aguiar. Rio de Janeiro: Civilização Brasileira, 2003. 235 p.

BUTLER, J. Undoing gender. New York and London: Routledge, 2004.

CARVALHO, J. G. da S. Mirem-se no exemplo daquelas mulheres... chinesas! (Representaçōes sociais, alteridade e Gênero). In: BRASIL. Presidência da República. Secretaria de Políticas para as Mulheres. $5^{\circ}$ Prêmio Construindo a Igualdade de Gênero. Redaçôes, artigos científicos e projetos pedagógicos vencedores. Presidência da República, Brasília: Secretaria de Políticas para as Mulheres, 2010, p. 18-38.

CASTELLS, M. A sociedade em rede. A era da informação: economia, sociedade e cultura. 2.ed., Trad.: Roneide Venancio Majer. São Paulo: Paz e Terra, 1999. v.1, 638p. 
FRIDMAN, L. C. Vertigens pós-modernas: configurações institucionais contemporâneas. Rio de Janeiro: Relume Dumará, 2000, 99 p.

GOFFMAN, E. Footing. In: B. T, RIBEIRO; P. M, GARCEZ. (Ed.). Sociolinguistica interacional. São Paulo: Edições Loyola, 2002. p.107-148.

GUMPERZ, J. C.; GUMPERZ, J. J. Commentary: frames and contexts: another look at the macromicro link. Pragmatics: 2011.21(2):283-286.

JAGOSE, A. Queer Theory. An Introduction. Nova York: New York University Press, 1996.

LOURO, G. L. Pedagogias da sexualidade. In: LOURO, G. L. (Ed.). O corpo educado: pedagogias da sexualidade. 2.ed. Trad.: Tomaz Tadeu da Silva. Belo Horizonte: Autêntica, 2000. p.9-34.

LOURO, G. L. Gênero e sexualidade: pedagogias contemporâneas. Disponível em: http://www.scielo.br/pdf/pp/v19n2/a03v19n2.pdf. 2008. Acesso em: 20/06/2013. MOITA LOPES, L. P. Linguística aplicada e vida contemporânea: problematização dos construtos que têm orientado a pesquisa. In: MOITA LOPES, L. P. (Ed.). Por uma linguistica aplicada indisciplinar. São Paulo: Parábola, 2006. p.85-107.

MOITA LOPES, L. P. “Se eu fosse mulher...": performances de gênero e sexualidade em Como gostais. In: MOITA LOPES, L. P. et al. (Ed.). Performances. Rio de Janeiro: Contra capa, 2007. p.79-102.

MOITA LOPES, L. P. Os novos letramentos digitais como lugares de construção de ativismo político sobre sexualidade e gênero. Trabalhos em Linguística Aplicada, Campinas, 2010, 49(2): 393-417.

MOITA LOPES, L. P. Identidades e pós-identidades. Disponível em: http://www. youtube.com/watch?v=6HDLg6_Jc7k. 2011. Acesso em: 23/04/2013.

NELSON, C. D. A Teoria Queer em linguística aplicada: enigmas sobre "sair do armário" em salas de aula globalizadas. In: MOITA LOPES, L. P. (Ed.). Por uma linguistica aplicada indisciplinar. São Paulo: Parábola, 2006. p.215-235.

PARK, J. S.; TAKANASHI, H. Introduction reframing framing: interaction and the constitution of culture and society. Pragmatics: 2011, 21(2):185-190. International Pragmatics Association.

PENNYCOOK, A. Uma linguística aplicada transgressiva. In: MOITA LOPES, L. P. (Ed.). Por uma linguistica aplicada indisciplinar. São Paulo: Parábola, 2006. p.67-84.

SALIH, S. Judith Butler e a Teoria Queer. Trad. Guacira Lopes Louro. Belo Horizonte: Autêntica Editora, 2012. 235 p. 
SANTAELLA, L. Linguagens líquidas na era da mobilidade. São Paulo: Paulus, 2007. 468 p.

Data de submissão: 16/06/2014. Data de aprovação: 12/08/2014. 